\title{
Ferroportin-1 is a 'nuclear'-negative acute-phase protein in rat liver: a comparison with other iron-transport proteins
}

\author{
Naila Naz*, Ihtzaz A Malik*, Nadeem Sheikh ${ }^{\dagger}$, Shakil Ahmad, Sajjad Khan, Martina Blaschke, Frank Schultze and \\ Giuliano Ramadori
}

Liver is the central organ of iron metabolism. During acute-phase-response (APR), serum iron concentration rapidly decreases. The current study aimed to compare expression and localization of iron transport protein ferroportin-1 (Fpn-1) and of other iron import proteins after experimental tissue damage induced by injecting turpentine oil in the hind limbs of rats and mice. Serum and spleen iron concentration decreased with an increase in total liver, cytoplasmic and nuclear iron concentration. In liver, mRNA amount of Fpn-1, Fpn-1a, Fpn-1b, HFE, hemojuvelin (HJV) and hephaestin (heph) genes showed a rapid decrease. Hepcidin, divalent metal transporter-1 (DMT-1), transferrin (Tf) and Tf-receptor-1 (TfR1), TfR-2 (TfR2) gene expression was increased. Western blot analysis of liver tissue lysate confirmed the changes observed at mRNA level. In spleen, a rapid decrease in gene expression of Fpn-1, Fpn-1a, Fpn-1b, DMT-1, Tf, TfR1 and TfR2, and an increase in hepcidin was observed. Immunohistochemistry of DMT-1 and TfR2 were mainly detected in the nucleus of rat liver and spleen, whereas TfR1 was clearly localized in the plasma membrane. Fpn-1 was mostly found in the nuclei of liver cells, whereas in spleen, the protein was mainly detected in the cell membrane. Western blot analysis of liver fractions confirmed immunohistochemical results. In livers of wild-type mice, gene expression of Fpn-1, Fpn-1a and Fpn-1b was downregulated, whereas hepcidin gene expression was increased. In contrast, these changes were less pronounced in IL-6ko-mice. Cytokine (IL-6, IL-1 $\beta$ and TNF- $\alpha$ ) treatment of rat hepatocytes showed a downregulation of Fpn-1, Fpn-1a and Fpn-1b, and upregulation of hepcidin gene expression. Moreover, western blot analysis of cell lysate of IL-6-treated hepatocytes detected, as expected, an increase of $\alpha 2$-macroglobulin (positive acute-phase protein), whereas albumin (negative acute-phase protein) and Fpn-1 were downregulated. Our results demonstrate that liver behaves as a 'sponge' for iron under acute-phase conditions, and Fpn-1 behaves as a negative acute-phase protein in rat hepatocytes mainly, but not exclusively, because of the effect of IL-6. These changes could explain iron retention in the cytoplasm and in the nucleus of hepatocytes during APR.

Laboratory Investigation (2012) 92, 842-856; doi:10.1038/labinvest.2012.52; published online 2 April 2012

KEYWORDS: acute phase protein; ferroportin-1; iron; iron regulatory protein; liver; nuclear expression

The liver is the central organ for iron metabolism. ${ }^{1}$ Liver cells (hepatocytes) take up iron absorbed from the diet, and Kupffer cells take up iron from aged erythrocytes and distribute it to different organs. Iron is an important co-factor for oxygen transport, heme and non-heme iron proteins, electron transfer, neurotransmitter synthesis, myelin production, energy metabolism and mitochondrial function, as well as for the production of reactive-oxygen species. ${ }^{2,3}$ As a result, its metabolism is tightly regulated. Iron homeostasis is controlled by a large group of iron-regulatory proteins. The absorption of dietary iron begins with its transport across the duodenal brush-border membrane mediated by the duodenal metal transporter-1 (DMT-1), the major iron transporter responsible for iron absorption in the duodenum. ${ }^{4}$ DMT-1 has been detected also in the endosomal compartment of different cells, suggesting that it participates in the transport of transferrin (Tf)-bound iron across the cellular membrane of acidified endosomes, resulting in the release of iron into the cytoplasm. ${ }^{5,6}$ After entering enterocytes, iron is used for essential metabolic purposes, stored in ferritin or translocated to

\footnotetext{
Division of Gastroenterology and Endocrinology, Department of Internal Medicine, University Hospital, Georg-August-University, Göttingen, Germany Correspondence: Professor G Ramadori, MD, Department of Internal Medicine, University Hospital Göttingen, Robert-Koch-Strasse 40, Göttingen 37075, Germany. E-mail: gramado@med.uni-goettingen.de

*These authors contributed equally to this work.

${ }^{\dagger}$ Current address: Department of Zoology, University of Punjab, Lahore, Pakistan. Received 28 November 2011; revised 8 January 2012; accepted 19 January 2012
} 
the portal blood by ferroportin-1 (Fpn-1). The plasma protein, $\mathrm{Tf}$, binds to diferric iron $\left(\mathrm{Fe}_{2} \mathrm{Tf}\right)$ and transfers it through portal blood to the liver, where either the Tf receptor- 1 (TfR1) ${ }^{7}$ or Tf-independent mechanism mediates hepatic uptake of iron. ${ }^{8}$ Interaction of iron bound to Tf with the TfR- 1 and internalization of the resultant complex leads to iron uptake in the cells as a result of receptor-mediated endocytosis. ${ }^{9}$ A second alternative $\mathrm{Tf}$-mediated route of iron uptake exists via TfR-2. Although the role of TfR-1 in transporting iron across the hepatocyte membrane is well defined, the role of TfR-2 is not yet fully understood. TfR-2 knock-out mice fail to reproduce as a result of embryonic lethality due to severe anemia. ${ }^{10}$ As TfR-2 mutations result in hepatic iron overload, TfR-2 appears to function, not principally in cellular iron uptake and delivery, but rather in iron storage. ${ }^{11}$

Fpn-1 (also known as MTP1, IREG-1 or SLC11A3) is the principal iron export protein in the cells. ${ }^{2,12}$ It was first characterized in zebrafish, in which embryos carrying mutations in the Fpn-1 ortholog showed a lack of ability to transfer iron from the yolk sac to the developing embryo. ${ }^{13}$ It is highly expressed in a large number of cells, to include duodenal enterocytes, reticuloendothelial macrophages ${ }^{2,13}$ and hepatocytes ${ }^{14}$ to mediate iron export. In the presence of an iron exporter (Fpn-1) and a ferroxidase namely hephaestin (heph), the newly released ferrous iron, is oxidized to its ferric form, allowing binding to $\mathrm{Tf}^{15} \mathrm{Heph}$ is thought to have a multi copper-oxidase activity due to its homology with ceruloplasmin. The co-localization of Fpn-1 and heph suggests a collaborative role of both proteins in the transport of iron out of enterocytes. ${ }^{16,17}$

The expression of Fpn-1 has been shown to be regulated by the liver-derived hormone, hepcidin. Hepcidin, the key mediator of iron metabolism, causes internalization and degradation of Fpn-1, resulting in a reduction of iron export with a resultant increase in cellular iron. ${ }^{2,18}$ Several studies have also demonstrated a direct regulatory effect of iron, ${ }^{19,20}$ IRP1 and IRP2 on the Fpn-1 gene expression. ${ }^{21}$

In addition, a recent study identified and characterized two isoforms of Fpn-1 (Fpn-1a and Fpn-1b), which differ from each other as a result of the presence or lack of an iron regulatory element. ${ }^{22}$ This suggests that the iron-regulatoryelement-acting isoform could escape repression by the IRE/ IRP system, which occurs in iron deficiency and allows for duodenum export of iron into the bloodstream to meet systemic iron demands. ${ }^{22,23}$

A characteristic response to tissue damage is a change in iron metabolism, beginning with an acute decline in serum iron level thought to be due to the sequestration of iron in organs of the reticuloendothelial system, mainly the liver and spleen. ${ }^{24}$ According to this hypothesis, macrophages sequester iron to prevent its availability to pathogens and its subsequent use for tissue repair and cell regeneration. However, this acute reduction of serum iron level is not only observed in cases of bacterial infections, but in all conditions associated with tissue damage ${ }^{24}$ as it has been reproduced in animal models. ${ }^{25,26}$
The mechanisms governing hepatic iron metabolism under acute-phase conditions is poorly understood. However, changes in the expression of iron metabolism proteins in both hepatic and non-hepatic organs, including the brain, have been reported in a rat model of the acute-phase response (APR). ${ }^{25,27,28}$ In addition, a significant increase in the hepatic content of iron has been reported in the rat model of turpentine oil (TO)induced muscle damage. ${ }^{25-27}$

In the present study, a reduction of the serum concentration associated with the increase in liver iron concentration ('sponge effect') is not paralleled by an increase in spleen iron concentration. The amount of nuclear iron increases significantly within the liver after the initiation of the APR. At the same time in the same organ (but not in the spleen), there is an increase in the proteins involved in serum iron uptake and transport (Tf, TfR1, TfR2 and DMT-1), whereas a reciprocal reduction in iron export proteins (Fpn-1 and hephastin) occurs. Therefore, Fpn-1 may be the first major 'nuclear'-negative acute-phase protein (APP), comparable to the major negative secretory APP, albumin, both of which are influenced mainly by the acute-phase mediator, IL-6, but also by IL- $1 \beta$ and TNF- $\alpha$.

\section{MATERIALS AND METHODS \\ Animals}

Rats (170-200 g body weight), were purchased from HarlanWinkelmann (Brochen, Germany). Adult male B6.129S2-116 ${ }^{\text {tmlKopf }}$ (IL-6 KO) mice and control wild-type adult male C57BL/6J mice (25-28 g body weight) were purchased from Jackson Laboratory. The animals were kept under standard conditions with 12:12-h light-dark cycles, and were given ad libitum access to water and food. All animals were cared for in accordance with the guidelines of our institution, the German Convention for the Protection of Animals, and the National Institutes of Health (USA).

\section{Induction of APR}

The APR was induced by injecting TO at a dose of $5 \mathrm{ml} / \mathrm{kg}$ body weight in rats and $10 \mathrm{ml} / \mathrm{kg}$ of body weight in mice. TO was injected into each hind limb gluteal muscle of etheranesthetized animals. Untreated animals served as controls. All animals were killed after the administration of pentobarbital anesthesia. ${ }^{29}$ Blood was obtained and serum was separated for subsequent studies. The liver and the spleen were removed, rinsed with physiological saline, frozen in liquid nitrogen, and stored at $-80{ }^{\circ} \mathrm{C}$ until used.

\section{Measurement of Iron Levels}

Serum and tissue iron levels were measured utilizing colorimetric ferrozine-based assay. ${ }^{30}$ To measure the iron concentration, tissue homogenates were prepared as reported previously. ${ }^{25}$ Iron was measured in both nuclear and cytoplasmic lysates from liver. Nuclear and cytoplasmic protein fractions were isolated as described previously. ${ }^{31}$ 


\section{Prussian Blue Iron Staining of Liver and Spleen}

Cryostat sections, $4 \mu \mathrm{m}$ thick (Reichert Jung, Wetzlar, Germany), were air dried at room temperature and used for iron detection using the Prussian blue technique, after fixation for $1 \mathrm{~min}$ in ice-cold acetone and $9 \mathrm{~min}$ in ice-cold methanol. Slides were stained with Accustains iron stain obtained from Sigma-Aldrich using the protocol provided by the manufacturer. Briefly, the tissue sections were hydrated in de-ionized water, placed in the iron staining solution for $10 \mathrm{~min}$, and then rinsed with de-ionized water. Slides were subsequently counterstained with pararosaniline for 3-5 min and rinsed again with de-ionized water, followed by a rapid dehydration with alcohol and xylene before mounting.

\section{RNA Isolation and Real-Time PCR Analysis}

RNA was isolated from liver and spleen from both control and treated rats, as well as from cultured cells as described previously. ${ }^{25}$ Reverse transcription of RNA into cDNA was performed utilizing the Superscript Kit (Invitrogen), according to the manufacturer's instructions. Real-time PCR analysis of cDNA was performed with the ABI Prism Sequence Detection System 7000 (Applied Biosystems, Foster City, CA, USA), using the SYBR-Green reaction master mix (Invitrogen) and the primers in Table 1. The primers were synthesized by MWG Biotech (Ebersberg, Germany). Two housekeeping genes $(\beta$-actin and $U B C)$ were used for normalization purposes. The control values were normalized to one, and the relative expression was plotted against the observation time. In all cases, two or three samples were analyzed in duplicate at each time point.

\section{Preparation of Tissue Lysates for Western Blot Analysis} Liver, spleen and cultured cells were lysed in RIPA buffer (25 mM Tris-HCl pH 7.6, $150 \mathrm{mM} \mathrm{NaCl}, 1 \% \mathrm{NP}-40,1 \%$ sodium deoxycholate, $0.1 \% \mathrm{SDS}$ ). The protein concentration was determined using the Bradford method (Pierce, Rockford, IL, USA). Nuclear and cytoplasmic protein fractions were isolated according to a previously described method. ${ }^{31}$ To obtain a membrane preparation, liver tissue was homogenized in $5 \mathrm{M} \mathrm{NaCl}, 1 \mathrm{M}$ Tris- $\mathrm{HCl} \mathrm{pH} 7.5,0.5 \mathrm{M}$ EDTA, $10 \mathrm{mg} / \mathrm{ml}$ PMSF, aprotinin and leupeptin, followed by centrifugation at 1000 r.p.m. for $10 \mathrm{~min}$, and collection of the pellet (membrane extract). The pellet was resuspended in lysis buffer (prepared as given above for the whole lysate) and stored at $-20^{\circ} \mathrm{C}$ for future use. Aliquots of $50 \mu \mathrm{g}$ of the proteins from each fraction was processed for immunoblotting as described previously, ${ }^{27}$ using the antibodies described in Table 2.

\section{Immunohistochemistry}

Cryostat sections, 4- $\mu \mathrm{m}$ thick (Reichert Jung, Wetzlar, Germany), were air-dried at room temperature and used for immunohistochemical studies after fixation for $1 \mathrm{~min}$ in acetone and 9 min in methanol. The antibodies used are listed in Table 2. Blocking of non-specific protein binding was performed utilizing goat serum for $1 \mathrm{~h}$ at room temperature. The slides were incubated overnight at $4{ }^{\circ} \mathrm{C}$ with the primary antibody diluted in 5\% Triton X-100 PBS buffer. Antigens were visualized using immunofluorescence and/or HRP-conjugated secondary antibodies. Negative-control immunostaining was performed by omitting the primary antibody and using an isotype-matching control immunoglobulin.

Table 1 Primers used in the study

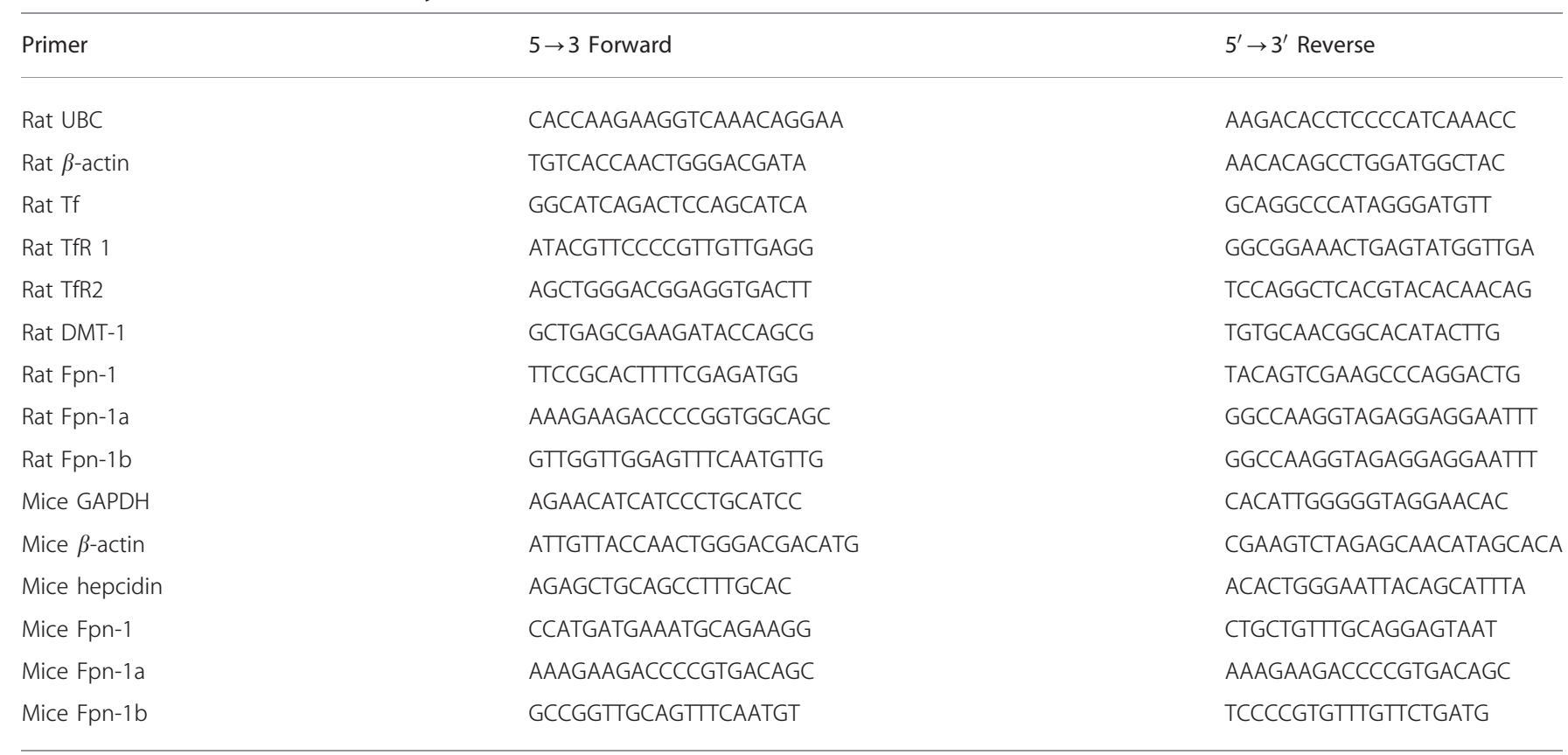


Table 2 Antibodies used in the study

\begin{tabular}{llllc}
\hline Antibodies & Reference & Species & \multicolumn{2}{c}{ Dilution } \\
\cline { 4 - 5 } & & & WB & IHC \\
& & & & \\
DMT-1 & Alpha-diagnostic & Rabbit & $1: 100$ & $1: 100$ \\
Tf & Abcam & Rabbit & $1: 1000$ & - \\
TfR-1 & Invitrogen & Mouse & $1: 500$ & $1: 1000$ \\
TfR-2 & Abcam & Rabbit & $1: 500$ & $1: 500$ \\
Fpn-1 & Pro-science, Abnova & Rabbit & $1: 500$ & $1: 250$ \\
ED-1 & Serotec & Mouse & - & $1: 100$ \\
Albumin & Dako & Rabbit & $1: 1000$ & - \\
a2M & Dako & Rabbit & $1: 1000$ & -
\end{tabular}

Abbreviations: $\alpha 2 \mathrm{M}$, alpha-2-macroglobulin; DMT-1, duodenal metal transporter-1; Fpn-1, ferroportin-1; IHC, immunohistochemistry; Tf, transferrin; TfR, Tf receptor.

\section{Isolation and Culture of Rat Liver Cells}

Rat liver cells (hepatocytes, Kupffer cells and myofibroblasts) were isolated and cultured as described previously. ${ }^{27}$ Hepatocytes were stimulated with a single treatment of $100 \mathrm{ng} / \mathrm{ml}$ of recombinant IL-6 (PeproTech, Germany), $100 \mathrm{ng} / \mathrm{ml}$ of recombinant IL- $1 \beta$ and TNF- $\alpha$ (PeproTech). Cells were harvested in all of the in vitro experiments after cytokine treatment. Non-treated cells at each studied time point served as controls.

\section{Statistical Analysis}

Densitometry of western blots was performed using Image J software (California, USA). Data were analyzed by Prism Graph-pad 4 software (San Diego, USA). The data are reported as the mean value \pm s.e.m. Statistical significance was calculated utilizing one-way analysis of variance (ANOVA) and the Dunnett post-hoc test, and was defined by a $P$-value $<0.05$.

\section{RESULTS}

\section{Serum and Tissue Iron Levels}

Compared with controls, the serum iron concentration decreased significantly during APR. This reduction reached a minimum $(41 \pm 1.5 \% ; P \leq 0.01$ vs control $)$ at $24 \mathrm{~h}$. At the same time, the hepatic iron concentration increased progressively during the APR. The increase reached its maximum $(141 \pm 3.2 \% ; P \leq 0.05 v s$ control $)$ at $12 \mathrm{~h}$. In contrast, spleenic iron levels did not increase. In fact, there was a nonsignificant reduction ( $75 \pm 13 \%$ of controls) in spleenic tissue iron content. Moreover, a significant increase in the iron content of the hepatic cytoplasmic and nuclear fraction was observed with the increase in the nuclear iron content $(160 \pm 3 \% ; P \leq 0.001$ vs control) being greater than the

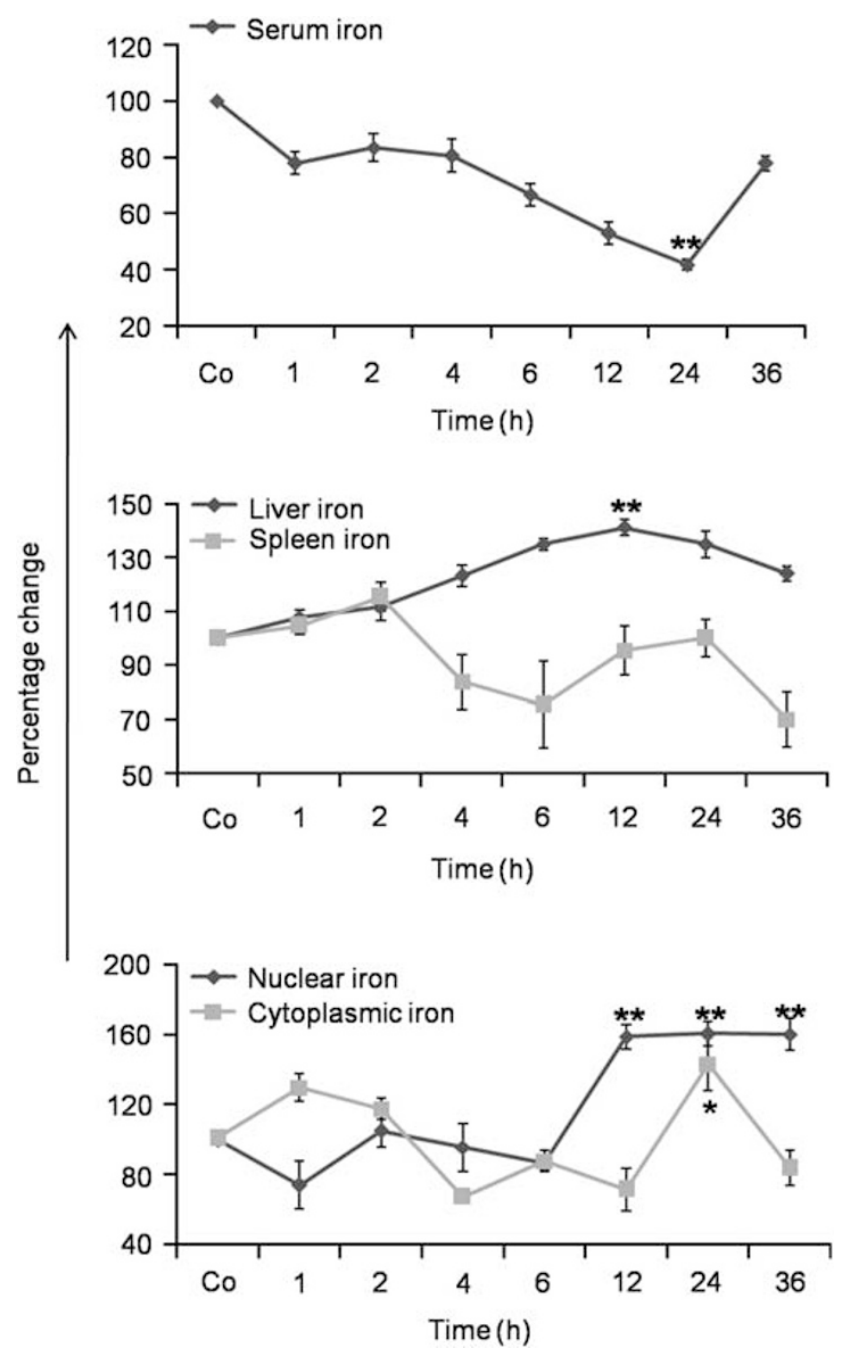

Figure 1 Changes of serum, liver, spleen and liver fraction iron content during rat acute-phase response (APR). Results show the percentage changes in iron content, where the $\mathrm{Co}$. (control) values were normalized to $100 \%$. Results represent mean values \pm s.e.m. ${ }^{* * P}<0.001$ analyzed by oneway analysis of variance (ANOVA); $n=3$ ).

cytoplasmic iron content $(141 \pm 5.4 \% ; P \leq 0.05 v s$ control $)$ at $24 \mathrm{~h}$ after APR (Figure 1).

\section{Prussian Blue Staining of Liver and Spleen Tissue}

Despite the findings reported above using cellular extracts, no difference in tissue iron identified by Prussian blue staining could be demonstrated. It is likely that the staining technique is less sensitive than the biochemical method used to demonstrate an increase in tissue iron. ${ }^{32}$

\section{Hepatic and Spleenic Changes in the Gene Expression of Iron Transport Proteins}

RT-PCR studies of total RNA obtained from liver showed an abrupt $(1 \mathrm{~h})$ and significant decrease in Fpn-1 (0.4 \pm 0.1 -fold), 
Fpn-1a (0.5 \pm 0.1 -fold), Fpn-1b $\quad(0.3 \pm 0.07$-fold $), \quad$ heph (0.4 \pm 0.01 -fold), HFE (0.3 \pm 0.1 -fold) and hemojuvelin (HJV) $(0.2 \pm 0.1$-fold $)$ gene expression, which continued to decrease for $24 \mathrm{~h}$. In contrast, the hepcidin gene expression started to increase $2 \mathrm{~h}$ after the onset of the APR, reaching a maximum at $6 \mathrm{~h}(7.4 \pm 0.01$-fold $)$. A similar rapid and significant increase in the DMT-1 gene expression was observed during the APR and reached a maximum at $12 \mathrm{~h}$ (2.9 \pm 0.3 -fold). An early and significant increase of the TfR 1 gene expression, which reached a maximum at $6 \mathrm{~h}(1.5 \pm 0.4)$ after the onset of the APR and a time-related increase $(1.3 \pm 0.1$-fold $)$ in Tf gene expression, were observed in liver tissue. Changes in the $T f R 2$ gene expression were less pronounced, but reached a maximum at the $6 \mathrm{~h}$ time point (Figure 2).
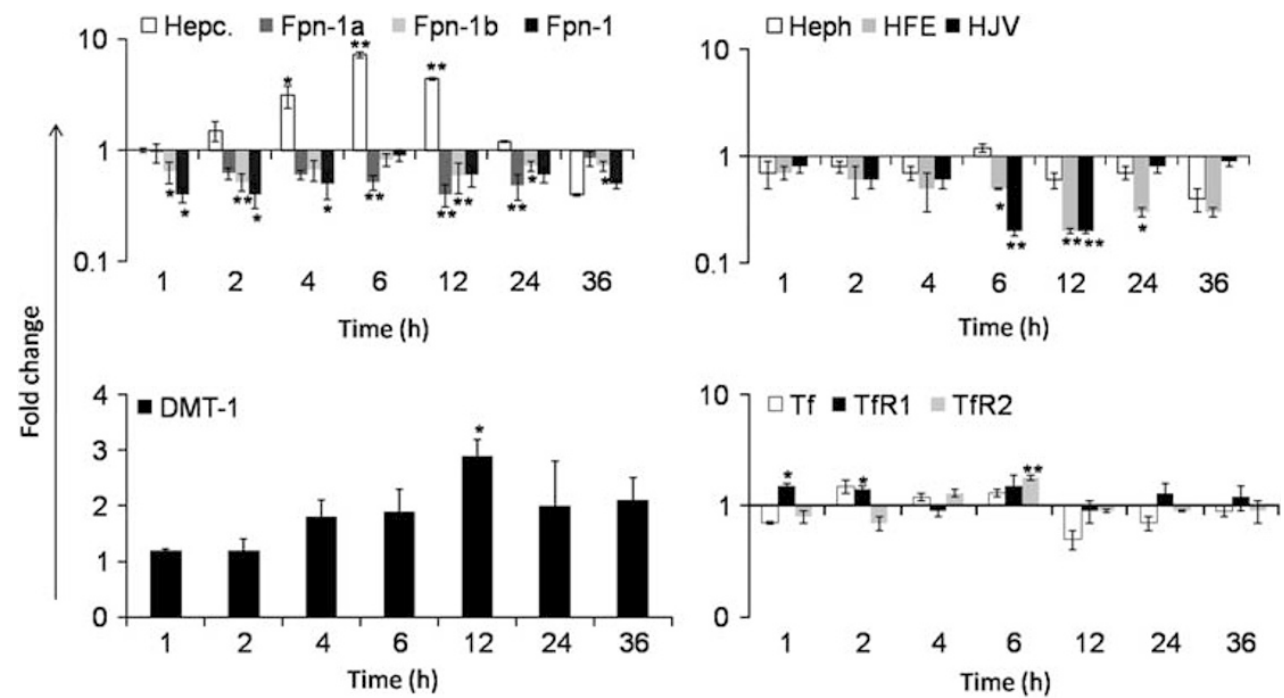

Figure 2 Reverse transcriptase (RT)-PCR analyses of genes involved in iron metabolism in rat liver during acute-phase response (APR). Gene expression of hepcidin, ferroportin-1 (Fpn-1), Fpn-1a, Fpn-16, hephaestin (heph), HFE, hemojuvelin (HJV), duodenal metal transporter-1 (DMT-1), transferrin (Tf), Tf receptor 1 and 2 (TfR1 and TfR2) in the rat liver during APR. Results represent the fold changes of mRNA expression of respective gene, where the control values were normalized to one. Data show the results of three animals (mean values \pm s.e.m.; ${ }^{*} P<0.05 ; * * P<0.001$ analyzed by one-way analysis of variance (ANOVA); $n=3$ ).
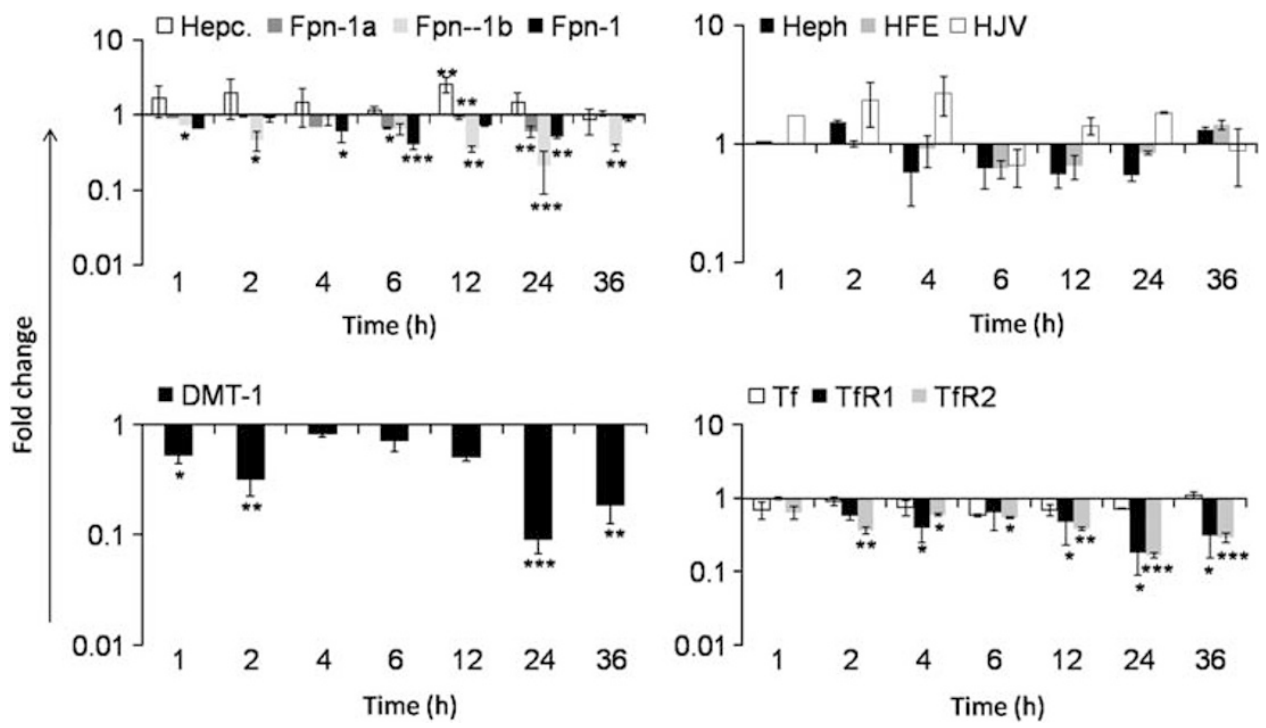

Figure 3 Reverse transcriptase (RT)-PCR analyses of genes involved in iron metabolism in rat spleen during acute-phase response (APR). Gene expression of ferroportin-1 (Fpn 1), Fpn-1a and b, hepcidin, hephaestin (heph), HFE, hemojuvelin (HJV), duodenal metal transporter-1 (DMT-1), transferrin (Tf), Tf receptors 1 and 2 (TfR1 and TfR2) in the rat spleen during APR. Results represent the fold changes of mRNA expression of respective gene where, the control values were normalized to one. Data show the results of three animals (mean values \pm s.e.m. ${ }^{*} P<0.05 ;{ }^{* * P}<0.001 ;{ }^{* *} P<0.0001$ analyzed by one-way ANOVA). 


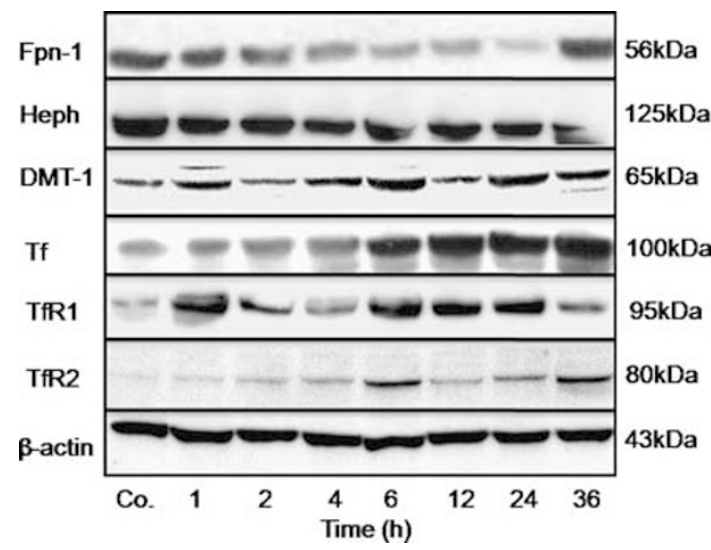

Figure 4 Western blot analysis of iron export proteins (ferroportin-1 $($ Fpn-1) and hephaestin (heph)) and the iron import proteins (duodenal metal transporter-1 (DMT-1), transferrin (Tf), Tf receptors 1 and 2 (TfR1 and TfR2)) in rat liver during acute-phase response (APR). The data shows a steep decrease in iron export (Fpn-1 and heph) protein expression together with an increase in iron import proteins (DMT-1, Tf, TfR1, and TfR2) expression. The results show representative figure from three experiments.
In spleen, a significant decrease in the mRNA expression of Fpn-1, Fpn-1a and Fpn-1b was observed early ( $1 \mathrm{~h})$ after APR and peaked for Fpn-1 at $6 \mathrm{~h}(0.3 \pm 0.02$-fold), for Fpn-1a at $24 \mathrm{~h}(0.6 \pm 0.08$-fold $)$ and for Fpn-1b at $24 \mathrm{~h}(0.2 \pm 0.03$-fold $)$. The mRNA expression of hepcidin was increased with a maximum ( $2.5 \pm 0.5$-fold $)$ at $12 \mathrm{~h}$. The DMT-1 gene expression was significantly downregulated $(0.10 \pm 0.02$-fold $)$ at $24 \mathrm{~h}$. The $T f$, $T f R 1$ and $T f R 2$ gene expression was downregulated throughout the study, with a minimum expression at $6 \mathrm{~h}$ for Tf $(0.7 \pm 0.01$-fold $)$, at $24 \mathrm{~h}$ for TfR $1(0.18 \pm 0.2$-fold $)$ and at $24 \mathrm{~h}$ for TfR2 $(0.16 \pm 0.1$-fold $)$. The changes in mRNA expression for heph, HFE and HJV were less pronounced, and in each case, were not statistically significant (Figure 3).

\section{Western Blot Analysis of Tissue Lysates}

Western blot analysis was performed to confirm at the protein level the changes observed at the mRNA level in rat liver (Figure 4). As observed at the mRNA level, the western blot analysis showed an early $(1 \mathrm{~h})$ reduction $(63 \pm 14 \%$ of
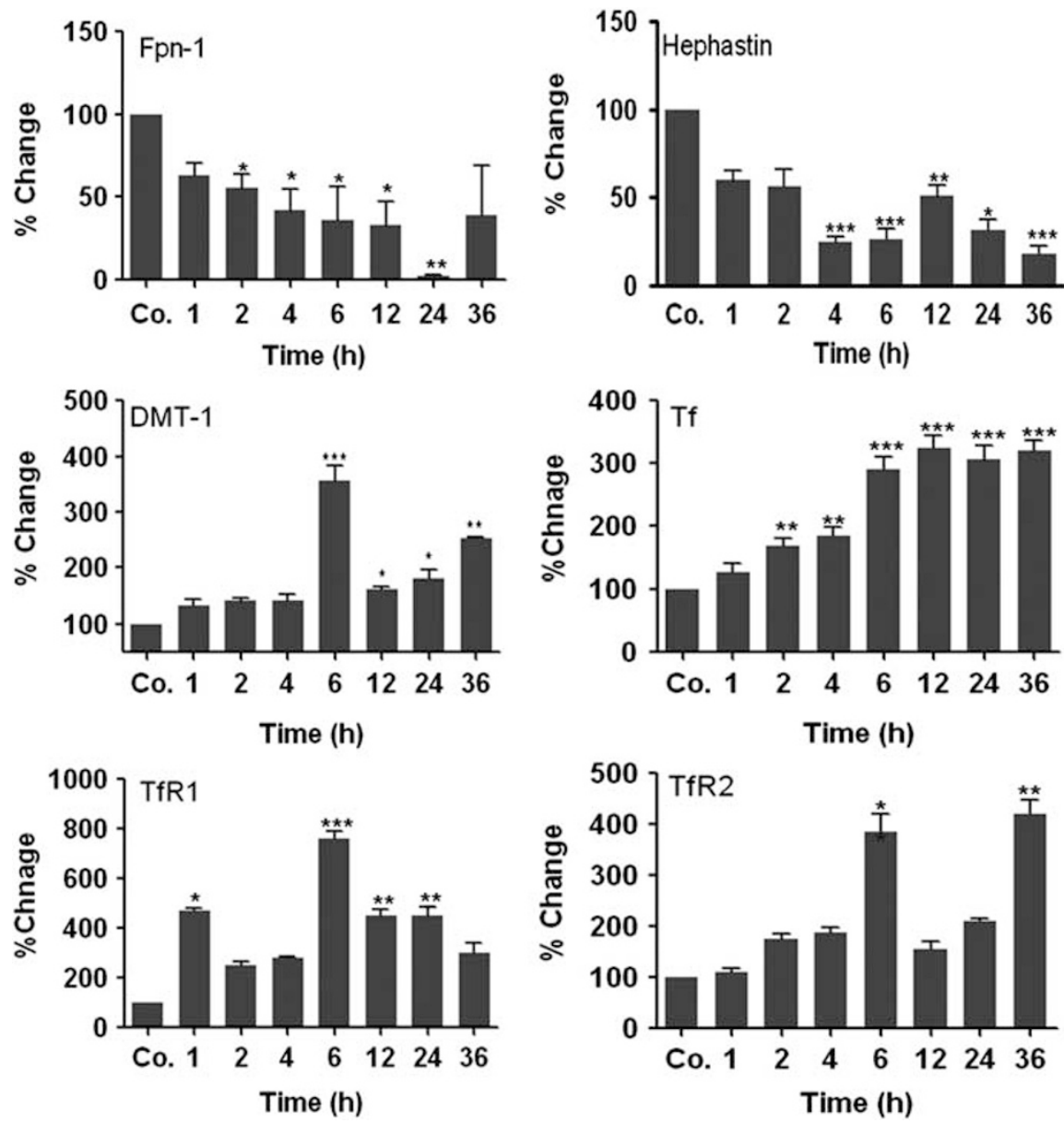

Figure 5 Densitometry analysis of Western blots performed for rat liver. The results show the significance of changes in the protein expression during acutephase response (APR). Results represent mean values \pm s.e.m. $\left({ }^{*} P<0.05,{ }^{* *} P<0.001,{ }^{* *} P<0.0001\right.$ analyzed by one-way analysis of variance (ANOVA); $n=3$ ). 
controls) of the iron export protein Fpn-1 and its protein expression was almost absent with an expression of only $1.2 \pm 0.5 \%$ of the controls at $24 \mathrm{~h}$ (Figure 4 and Supplementary Figure 1). Hephaestin protein expression was decreased as well, early $(1 \mathrm{~h})$ after the onset of acute-phase reaction, with expression reduced to $15 \pm 5 \%$ of controls at $36 \mathrm{~h}$. Western blot analysis of DMT-1 revealed two immunoreactive bands for the protein at 65 and $34 \mathrm{kDa}$. Similar to what was observed at mRNA level, the amount of DMT-1 protein gradually increased with a maximum expression $(370 \pm 10 \%)$ of controls by $6 \mathrm{~h}$. Similarly, a steep increase in $\mathrm{Tf}$ (the iron-binding and transport protein) was observed at the protein level, which reached $320 \pm 10 \%$ of controls. Moreover, a quick $(1 \mathrm{~h})$ and intense increase in the TfR1 protein was observed after the initiation of the APR, which reached a level $800 \pm 30 \%$ of controls at $6 \mathrm{~h}$. A gradual increase in TfR2 protein was observed, although the magnitude of the increase was less than that observed for the TfR1 protein, TfR2 levels reached a maximum of $420 \pm 30 \%$ of controls by $6 \mathrm{~h}$ (Figure 5).

\section{Immunohistochemical Detection of Fpn-1 in Liver and Spleen}

Immunohistochemical analysis was performed to investigate the cellular localization of Fpn-1 in hepatic tissue. Immunoreaction of Fpn-1 was found mainly in the nuclei (dot spot) of hepatocytes (Figure 6 and Supplementary Figure 2). However, the intensity of nuclear staining for Fpn-1 was reduced during ARP. To identify other cell types expressing Fpn-1 protein, double immunofluoresence staining was performed utilizing the ED-1 (macrophage marker), and revealed co-expression of Fpn1 and ED-1 in the Kupffer cells. Fpn-1 immunodetection was then analyzed in the spleen, where it was localized in the cell membranes of the white and red pulp cell populations (Figure 6). The results were confirmed using two different antibodies against the Fpn-1 protein mentioned in 'Antibodies' in Table 2.
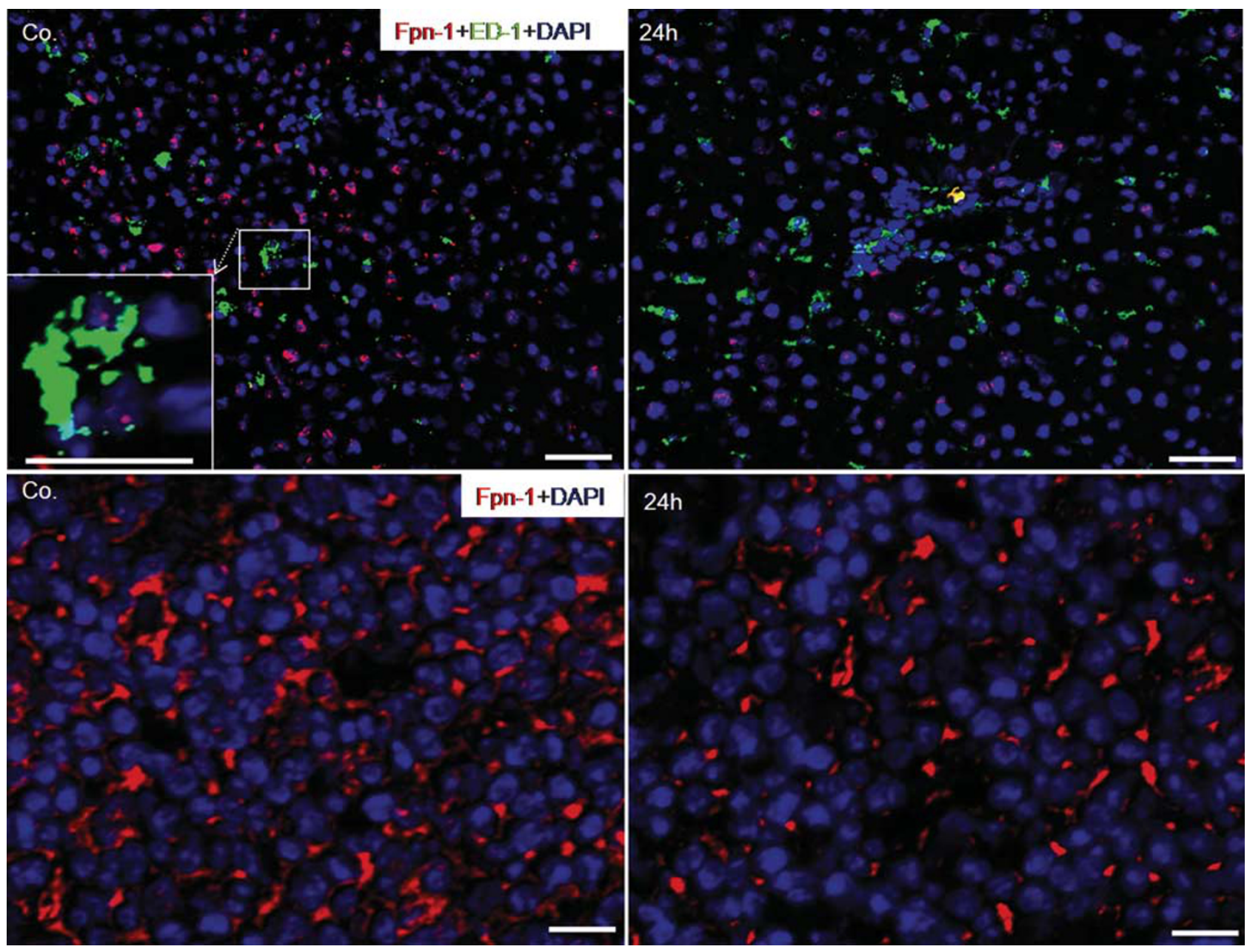

Figure 6 Immunohistochemistry of ferroportin-1 (Fpn-1) protein in rat liver and spleen during acute-phase response (APR). Upper panel; double immunofloresence indicating ED-1 (green) and Fpn-1 (red) in liver of control and terpentine oil (TO)-injected rats. Original magnification $\times 200$. Scale bar equals $50 \mu \mathrm{m}$. Lower panel; identification of $\mathrm{Fpn}-1$ protein in spleen of control and TO-injected rats $(\mathrm{Co}=$ control). Original magnification $\times 400$. Scale bar equals $25 \mu \mathrm{m}$. 
Furthermore, the reaction was negative when anti-Fpn-1 antibody was blocked by the immunizing peptide in liver tissue (Supplementary Figure 3) or the first antibody was omitted.

\section{Immunohistochemical Detection of DMT-1 in Liver and Spleen}

DMT-1 protein was clearly detectable within the large nuclei of the hepatocytes (easily identifiable by their size; Figure 7 and Supplementary Figure 2) of both control and TOinjected rats. It was organized in well-defined spots, and the intensity of these dots increased by $6 \mathrm{~h}$ after the onset of APR. Additional double immunostaining with ED-1 showed a co-expression of ED-1-positive cells (macrophages) with DMT-1 protein (Figure 7, upper panel). Similarly, DMT-1 was detected in the nuclei of white and red pulp cell population of the spleen. The nuclear expression of DMT-1 located in the red pulp area of spleen was decreased during the acute-phase reaction (Figure 7, lower panel). Furthermore, the reaction was negative when anti-DMT-1 antibody was blocked by the immunizing peptide in liver tissue (Supplementary Figure 3) or the first antibody was omitted.

\section{Immunohistochemical Detection of TfR1 in Liver and Spleen}

Immunohistochemical investigation of the control and TO-injected rat livers showed hepatic membranous and cytoplasmic expression of TfR-1 in both hepatocytes and sinusoidal cells (Figure 8 and Supplementary Figure 2). The intensity of membranous TfR1 protein expression increased during the APR. Similarly, in spleen, TfR1 was localized to the cell membrane of both the white and red pulp cell populations, being more prominent in the red pulp area (Figure 8).

\section{Immunohistochemical Detection of TfR2 in Rat Liver and Spleen}

Interestingly, immunodetection of TfR-2 protein was stronger in the large nuclei of liver cells (Supplementary Figure 2),
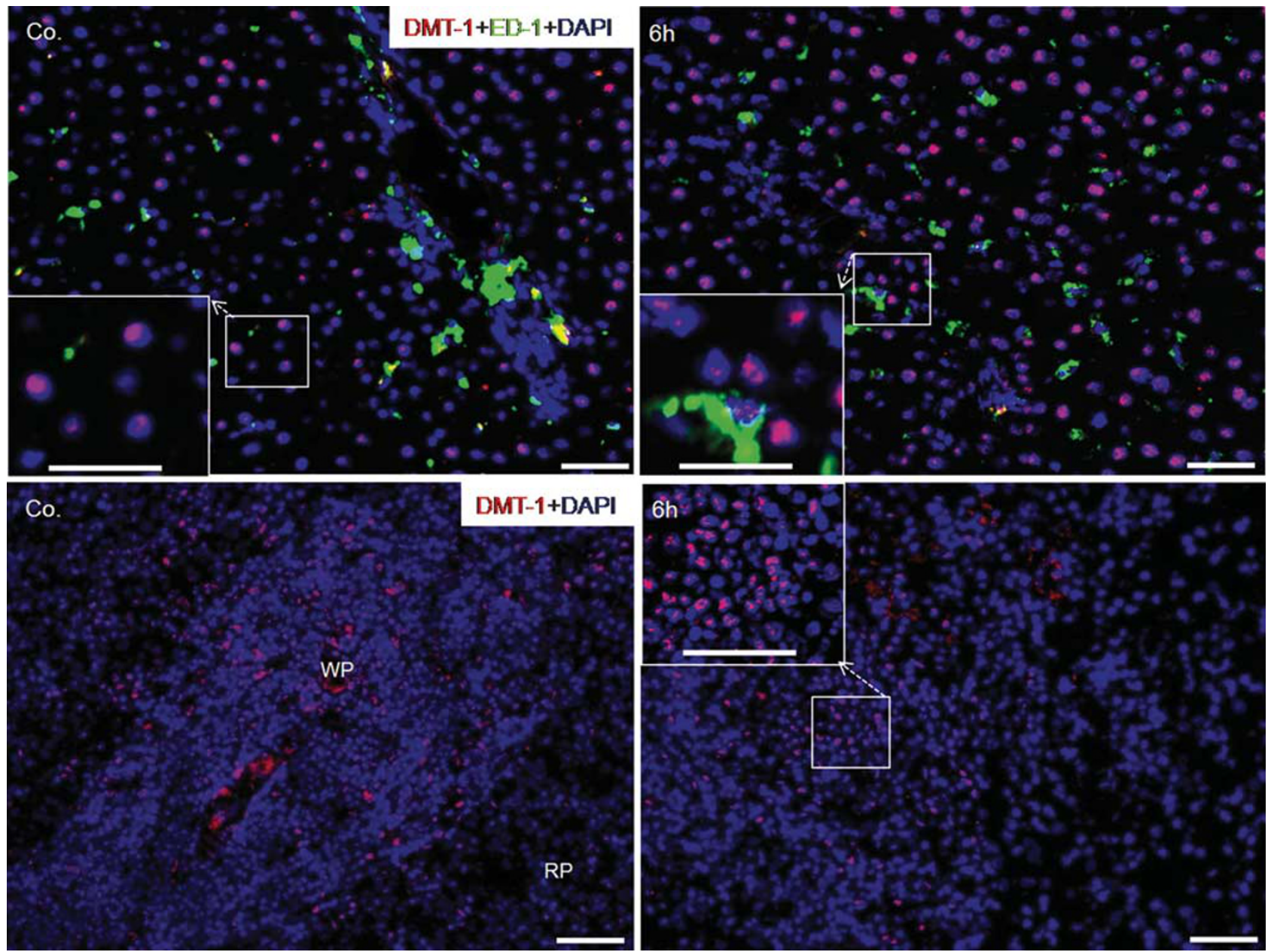

Figure 7 Immunohistochemistry of duodenal metal transporter-1 (DMT-1) protein in rat liver and spleen during acute-phase response (APR). Upper panel; double immunofloresence indicating ED-1 (green) and DMT-1 (red) in control and acute-phase livers. Lower panel; identification of DMT-1 protein in spleen of control and acute-phase rats $(\mathrm{Co}=$ control, $\mathrm{RP}=$ red pulp, WP $=$ white pulp). Original magnification $\times 200$. Scale bar equals $50 \mu \mathrm{m}$. 

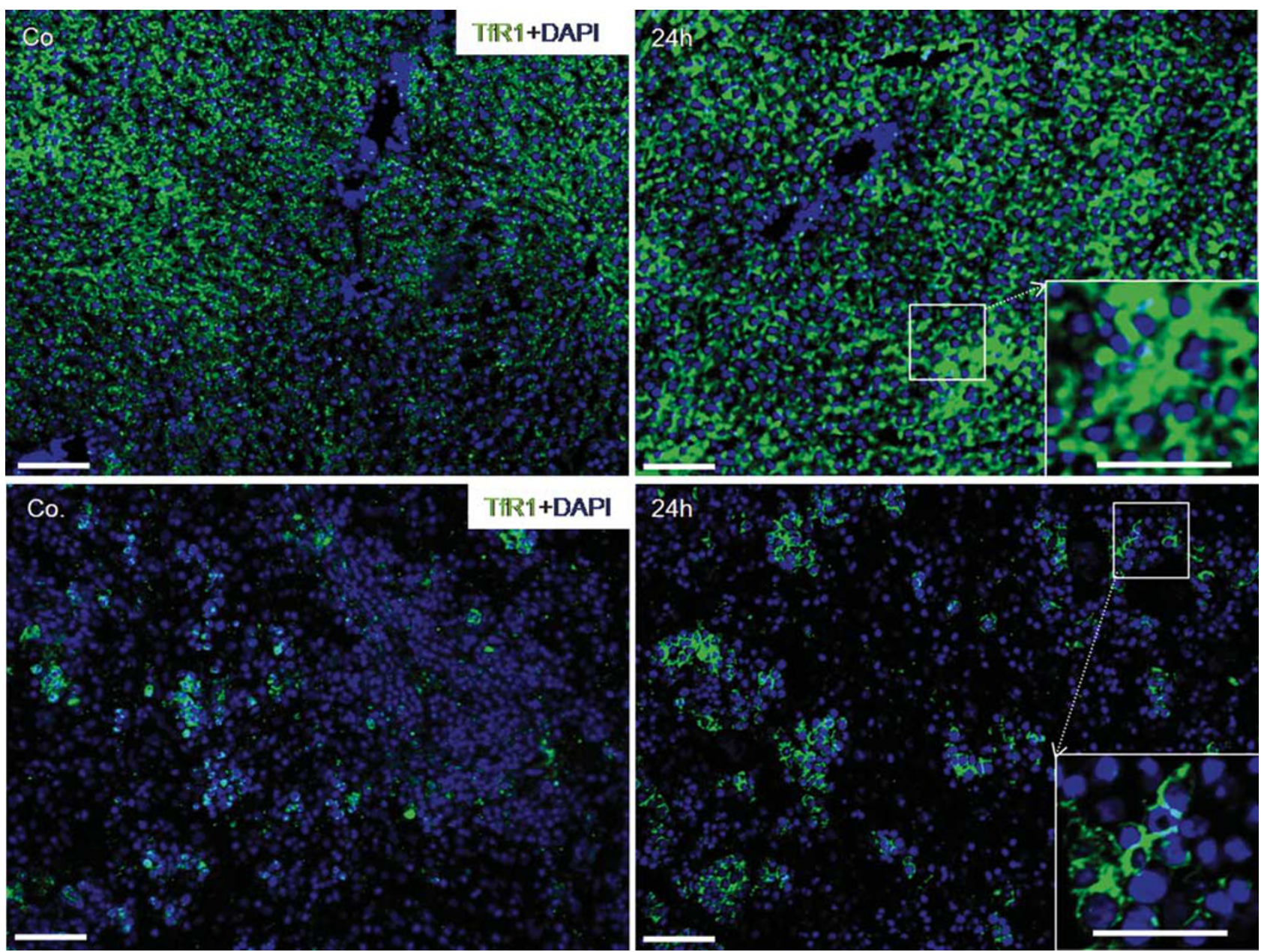

Figure 8 Immunohistochemistry of transferrin receptor 1 (TfR1) protein in rat liver and spleen during acute-phase response (APR). Upper panel; TfR1positive cells (green) in control and $24 \mathrm{~h}$ after APR. Lower panel; identification of TfR1 protein in spleen of control and $24 \mathrm{~h}$ after $\mathrm{APR}(\mathrm{Co}=\mathrm{control}, \mathrm{RP}=\mathrm{red}$ pulp, WP $=$ white pulp). Original magnification $\times 200$. Scale bar equals $50 \mu \mathrm{m}$.

and disperse dots were detected in the cytoplasm. Additionally, double immunofluorescent staining for TfR2 and ED-1 revealed a co-expression of both proteins. Similarly, an intense nuclear positivity for TfR2 was detected in the cells of the white pulp area of the spleen (Figure 9).

\section{Immunoblotting of Iron Transport Proteins in Tissue Fractions}

The immunohistochemical results were further confirmed by means of western blot analysis of isolated protein fractions (cytoplasmic, membrane and nuclear) from liver tissues. Immunoblotting detected Fpn-1, DMT-1 and TfR-2 in the nuclear fraction, and only weakly in the cytoplasmic fraction. In contrast, Tf and TfR-1 were detected only in the cytoplasmic and membrane fractions (Figure 10a).

\section{Expression of Iron Transport Proteins in Isolated Liver Cells}

The specific type of liver cells expressing the major iron transport proteins was further confirmed by means of western blot analysis of total proteins from cultured liver cells. Among the major liver cell types (hepatocytes, Kupffer cells and myofibroblasts), Fpn-1, DMT-1, Tf, TfR-1 and TfR-2 protein expression was identified in isolated rat hepatocytes and Kupffer cells; only TfR1 was also clearly detectable in myofibroblasts (Figure 10b).

\section{Changes in the Expression Pattern of Fpn-1, Fpn-1a, Fpn-1b and Hepcidin in Mouse Liver}

To further investigate the role of major acute-phase cytokine (IL-6) in the hepatic Fpn-1 gene regulation, the mRNA expression of Fpn-1 and its isoforms, together with hepcidin, was analyzed in the liver of wild-type and IL- 6 knock-out mice before and after intramuscular TO injection. RT-PCR displayed an upregulation of hepcidin gene expression in wild-type and IL-6 knock-out mice. However, in wild-type mice, the constitutive expression of hepcidin was greater $(3.5 \pm 0.5$-fold $)$ than in the IL-6 knock-out animals (1.5 \pm 0.1 -fold) by $12 \mathrm{~h}$ after APR. Moreover, Fpn-1, Fpn-1 $a$ and 

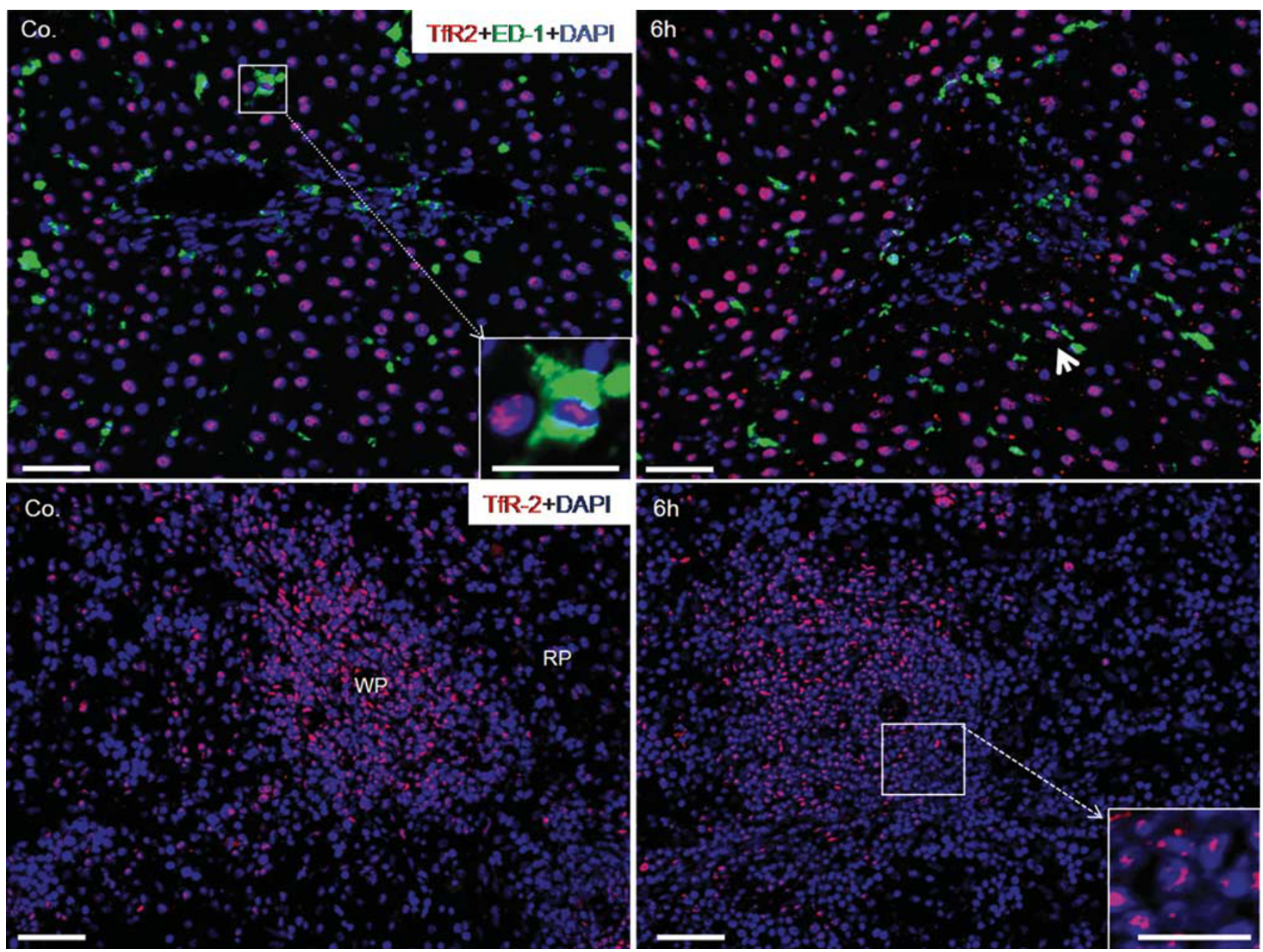

Figure 9 Immunohistochemistry of transferrin receptor 2 (TfR2) protein in rat liver and spleen during acute-phase response (APR). Upper panel; double immunofloresence indicating ED-1 (green) and TfR2 (red) in the liver of control and terpentine oil (TO)-injected rats. Lower panel; identification of TfR2 protein in spleen of control and TO-injected rats $(\mathrm{Co}=$ control, $\mathrm{RP}=$ red pulp, WP $=$ white pulp). Original magnification $\times 200 . \mathrm{Scale}$ bar equals $50 \mu \mathrm{m}$.

Fpn-1b gene expression was downregulated in both the wildtype and IL-6 knock-out mice during the APR. However, the reduction in mRNA for Fpn-1 and its isoforms was intense in wild-type mice than in the IL-6 knock-out animals. In wildtype mice, the lowest level of Fpn-1 (0.3 \pm 0.1 -fold) occurred at $12 \mathrm{~h}$, whereas in the IL- 6 knock-out mice it was less $(0.7 \pm 0.1$-fold $)$ and occurred at $4 \mathrm{~h}$. Similarly, in wild-type mice, Fpn-1a declined to its minimum value $(0.3 \pm 0.03$-fold $)$ by $6 \mathrm{~h}$, and in the IL- 6 knock-out mice, the reduction was less $(0.73 \pm 0.04$-fold $)$ and occurred earlier, ie, $4 \mathrm{~h}$ of APR. The decrease of Fpn-1b mRNA expression in wild -type mice was $(0.5 \pm 0.1$-fold $)$ by $2 \mathrm{~h}$, and in IL- 6 knock-out mice, it was similar to wild-type mice $(0.4 \pm 0.06$-fold $)$, but occurred later at $(4 \mathrm{~h})$ of APR (Figure 11). Table 3 illustrates the changes in mRNA of Fpn-1 and its isofroms in both wild-type and IL-6 knock-out-mice.

The western blot analysis of wild-type mice indicated a reduction in Fpn-1 protein expression at $2 \mathrm{~h}$ after the APR, which became almost undetectable at $24 \mathrm{~h}$, similar to what was observed in rat liver. In the IL-6 knock-out mice, on the other hand, only a minor reduction in Fpn-1 protein expression was observed during APR (Figure 12).

\section{Changes in mRNA Expression Pattern of Fpn-1 and Hepcidin in Rat Hepatocytes After Cytokine Treatment} To demonstrate the direct effect of IL-6 on hepatocyte Fpn-1 gene regulation, rat hepatocytes were isolated, cultured and stimulated with recombinant IL-6. The mRNA expression of Fpn-1, Fpn-1a and Fpn-1b decreased early ( $1 \mathrm{~h}$ ) after stimulation with IL-6. This reduction was statistically highly significant $(P \leq 0.0001)$ for $F p n-1 \quad(0.11 \pm 0.07$-fold of controls) at $12 \mathrm{~h}$, for Fpn-1a (0.11 \pm 0.04 -fold of controls) at $24 \mathrm{~h}$ and for Fpn-1b (0.10 \pm 0.03 -fold of controls) at $24 \mathrm{~h}$. In contrast, the mRNA expression of hepcidin was upregulated, achieving a maximum at $6 \mathrm{~h}$ after IL-6 stimulation (9.0 \pm 1.9 fold of controls; Figure 13).

To address the question of the Fpn-1 downregulation tendency in IL-6 knock-out mice and the effect of other acute-phase cytokines (IL- $1 \beta$ and TNF- $\alpha$ ) on the Fpn-1 gene regulation, rat hepatocytes were stimulated with either IL-1 $\beta$ 

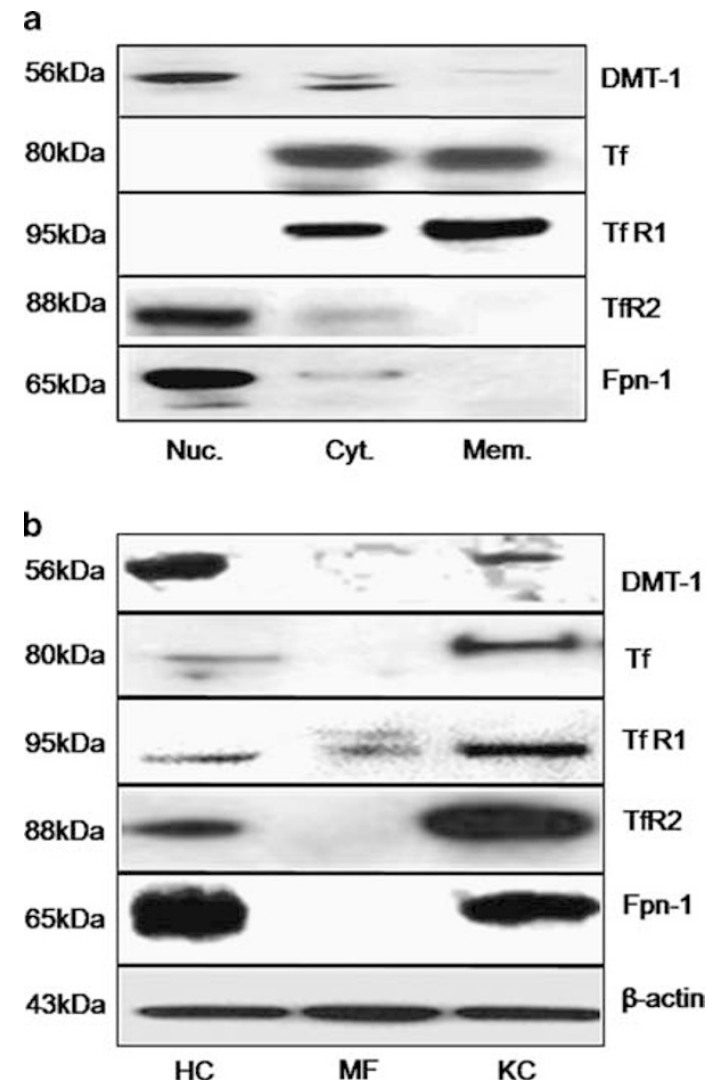

Figure 10 Western blot analysis of duodenal metal transporter-1 (DMT-1), transferrin (Tf), Tf receptor 1 and 2 (TfR1 and TfR2) and ferroportin-1 (Fpn-1). (a) Expression of iron transport proteins in control liver tissue fractions (Nuc.: nuclear extract, Cyto.: cytoplasmic extract, Memb.: membrane extract). (b) Comparative expression of iron transport proteins in major cell population of rat liver in (HC: hepatocytes, MF: myofibroblasts, KC: Kupffer cells). $\beta$-actin was used as a loading control. Results represents representative figure of three experiments.

or TNF- $\alpha$, and the gene expression of hepcidin, Fpn-1, Fpn-1a and $F p n-1 b$ was analyzed by RT-PCR. As observed for normal hepatocytes after IL-6 stimulation, the mRNA expression of Fpn-1, Fpn-1 $a$ and Fpn-1b decreased with either IL-1 $\beta$ or TNF- $\alpha$ stimulation. This reduction reached its nadir for Fpn-1 $(0.31 \pm 0.15$-fold of controls $)$ at $12 \mathrm{~h}$ after IL- $1 \beta$ stimulation and ( $0.24 \pm 0.16$-fold of controls) at $6 \mathrm{~h}$ after TNF- $\alpha$ stimulation. For $F p n-1 a$, the nadir was $0.33 \pm 0.07$-fold of controls at $6 \mathrm{~h}$ after IL- $1 \beta$ stimulation and $0.6 \pm 0.23$-fold of controls after TNF- $\alpha$ stimulation, and for Fpn-1b $(0.20 \pm 0.15$-fold of controls) after IL- $1 \beta$ stimulation and $(0.50 \pm 0.25$-fold of controls) after TNF- $\alpha$ stimulation. The mRNA expression of the hepcidin gene was upregulated reaching a maximum at $12 \mathrm{~h}$ after IL- $1 \beta$ stimulation $(2.02 \pm 0.2$-fold of controls) and (2.5 \pm 0.23 -fold of controls) after TNF- $\alpha$ stimulation (Figure 14). The changes in mRNA expression of Fpn-1 and its isoforms after cytokine (IL-6, IL- $1 \beta$ and TNF- $\alpha$ ) stimulation is shown in Table 4, which also demonstrate that the reduction is the greatest in hepatocytes after IL-6 stimulation (Table 4).

\section{Protein Changes of Fpn-1 in Rat Hepatocytes After IL-6 Treatment}

After IL-6 treatment, acute-phase conditions were confirmed in hepatocytes by an upregulation of positive APP; alpha-2macroglobulin and a downregulation of the negative APP, albumin. Immunoblotting for Fpn-1 documented a downregulation of Fpn-1 protein expression following IL-6 treatment, supporting a direct regulatory effect of IL-6 on rat hepatocytes (Figure 15).

\section{DISCUSSION}

In a model of acute-phase reaction induced by tissue (muscle) damage at a site distant from the liver, where the liver becomes a target of the acute-phase cytokines (mainly IL-6 in the present model of study), ${ }^{25}$ a time-dependent increase in total hepatic cytoplasmic, and even greater increase in nuclear iron concentration, but not in the spleenic iron, with a parallel reduction of the serum iron concentration is demonstrated. Determination of non-heme iron deposition in different organs under normal conditions has already been attempted. ${ }^{33}$ Furthermore, previous studies have shown that iron-loading in HFE knock-out mice with hemochromatosis also resulted in limited increased iron deposition within the spleen. ${ }^{34,35}$ However, so far, no data is available about comparison of the changes of iron content in liver ${ }^{25}$ with those taking place in the spleen during acute-phase reaction to tissue damage.

As we and others ${ }^{27,36}$ have shown, TfR 1 is localized in the plasma membrane of the hepatocytes and Kupffer cells. In contrast, a remarkable finding of current study was to detect a strong nuclear positivity for TfR2, DMT-1 and Fpn-1 by immunohistology. Using the same antisera, these findings were further confirmed by western blot analysis of membrane, cytoplasmic and nuclear fractions obtained from total liver lysates. Western blot analysis also showed a very weak cytoplasmic positivity for TfR2, DMT-1 and Fpn-1. One possible explanation for this finding could be that the cytoplasm of hepatocytes contains a higher number of proteins with relatively low concentration as compared with the nucleus; this could make nuclear immunodetection by immunofloresence and by immunoblotting easier.

Our finding suggests that iron sequestration occurs not only within the cytoplasm, but also within the nucleus of liver cells, and hypothesizes an important role of nuclear iron in hepatocyte metabolism under 'stress' conditions. In fact, under acute-phase conditions, additional iron may be needed to satisfy the increased metabolic work of the liver. ${ }^{37}$ Increased level of nuclear iron may be necessary for the increased activity of nuclear enzymes involved in DNA synthesis, repair and regulation of transcription as it has been hypothesized for rat adrenal cell lines. ${ }^{38}$ An earlier study reported evidence of stainable iron within the nucleus of hepatocytes and Kupffer cells under conditions of iron overload. $^{39}$ 

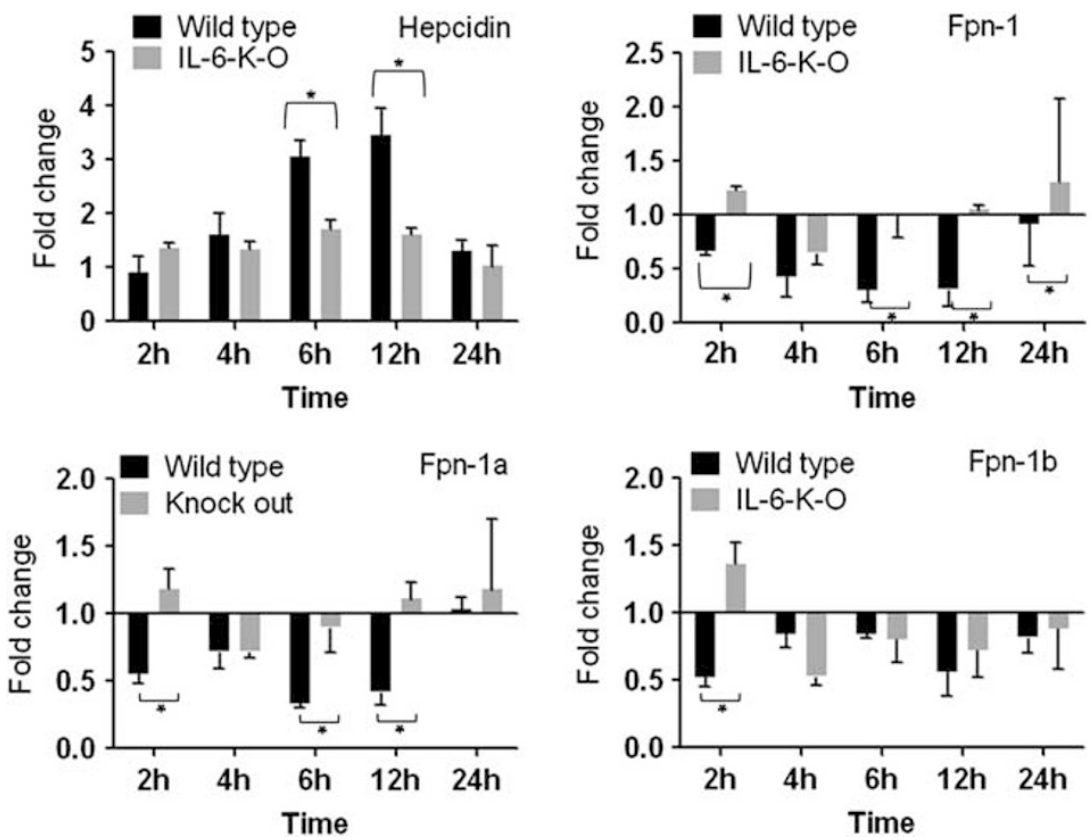

Figure 11 Gene expression of hepcidin, ferroportin-1 (Fpn-1), Fpn-1a and Fpn-1b in wild-type (black bars) and IL-6 knock-out (gray bars) mice liver during acute-phase response (ACR). Reverse transcriptase (RT)-PCR was normalized by using ubiquitin $C$ as housekeeping gene. Results represent the fold changes of mRNA expression of respective gene, where the control values were normalized to one. Data show the results of three animals (mean values \pm s.e.m. ${ }^{*} P<0.005$ analyzed by one-way analysis of variance (ANOVA)).

Table 3 Comparison of changes in mRNA amount of Fpn-1 and its isoforms in wild-type and IL-6 knock-out mice during APR

\begin{tabular}{lcc} 
Gene & Changes in mRNA amount of Fpn-1 and its isoforms \\
\cline { 2 - 3 } & Wild-type mice & IL-6 knock-out mice \\
\hline Fpn-1 & $0.3 \pm 0.1$ & $0.70 \pm 0.1$ \\
Fpn-1a & $0.3 \pm 0.03$ & $0.73 \pm 0.04$ \\
Fpn-1b & $0.5 \pm 0.1$ & $0.4 \pm 0.06$ \\
\hline
\end{tabular}

Abbreviations: APR, acute-phase response; Fpn-1, ferroportin-1.
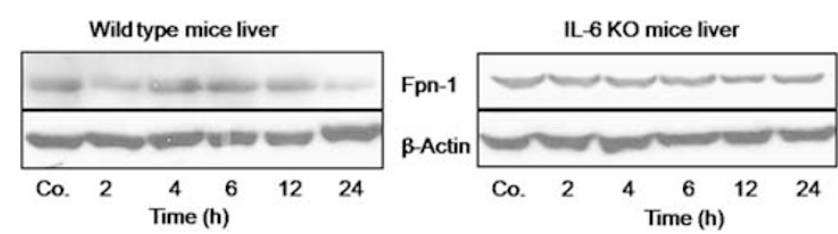

Figure 12 Western blot analysis of hepatic ferroportin-1 (Fpn-1) protein in wild-type and IL- 6 knock-out mice during acute-phase response (APR). The result shows an intense decrease of Fpn-1 protein in wild-type mice, which was almost undetectable during $24 \mathrm{~h}$ of APR. However, in IL- 6 knock-out mice, the changes of Fpn-1 protein were less pronounced.

To the best of our knowledge, nuclear expression of DMT-1, TfR-2 and Fpn-1 in rat liver under normal and acute-phase conditions has not been described previously. As increasing amounts of iron seem to be temporarily needed in the nucleus during the acute-phase reaction, it is not surprising to detect iron transport proteins not only in cytoplasm, but also in the nucleus of the liver cells. Previous studies reported nuclear expression of ferritin under iron overload condition in mice liver, ${ }^{40}$ and a migration of ferritin $\mathrm{H}$ isoform into the nucleus of human astrocytoma cells in presence of iron has been described. ${ }^{41}$

Cellular localization of Fpn-1 has been controversially debated. Previous reports found Fpn- 1 expression in plasma membrane of enterocytes, ${ }^{42}$ Kupffer cells and hepatocytes. ${ }^{23,43}$ Supranuclear ${ }^{44}$ and nucleolus ${ }^{45}$ localization of Fpn-1 in different organs of human and mouse other than liver has also been reported. At the moment, we cannot exclude the possibility of hepatic Fpn-1 plasma membrane presence, but our current study clearly showed nuclear Fpn-1 detection different than that of membranous TfR 1 .

In the current study, the mRNA expression, Western blot analysis and immunohistochemical findings using rat liver sections, all support an early and intense decrease of Fpn-1 expression before hepcidin gene expression starts to increase within the liver under the acute-phase conditions studied. A similar pattern of Fpn-1 reduction was observed in the liver of wild-type (C57 black) mice after TO injection. In contrast, a marginal upregulation of hepcidin, and downregulation of Fpn-1- and its isoforms gene expression in IL-6 knock-out mice under acute-phase conditions might be due to the effect of other acute-phase cytokines such as IL- $1 \beta$, and to a lesser extent, to TNF- $\alpha$, which are also produced at the site of tissue 


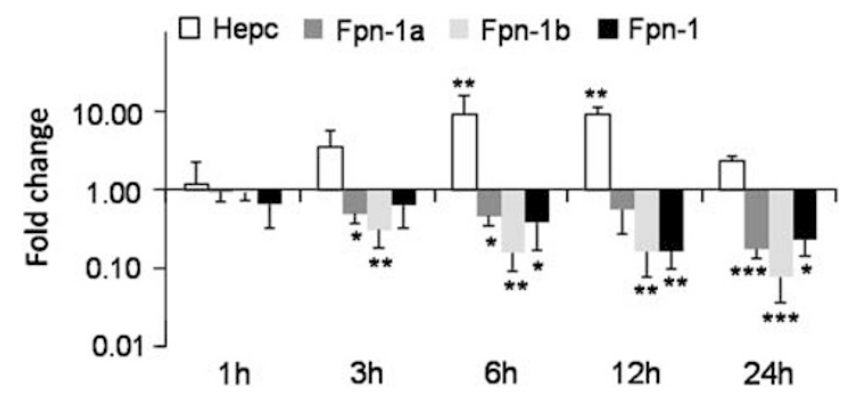

Figure 13 Quantification of hepcidin, ferroportin-1 (Fpn-1), Fpn-1a and $F p n-16$ gene expression in isolated rat hepatocytes after IL-6 treatment. Results represent the fold changes of mRNA expression of respective gene, where the control values were normalized to one. Data show the results of three experiments (mean values \pm s.e.m., ${ }^{*} P<0.05$; ${ }^{* * P}<0.001 ;{ }^{* *} P<0.0001$ analyzed by one-way analysis of variance (ANOVA)).

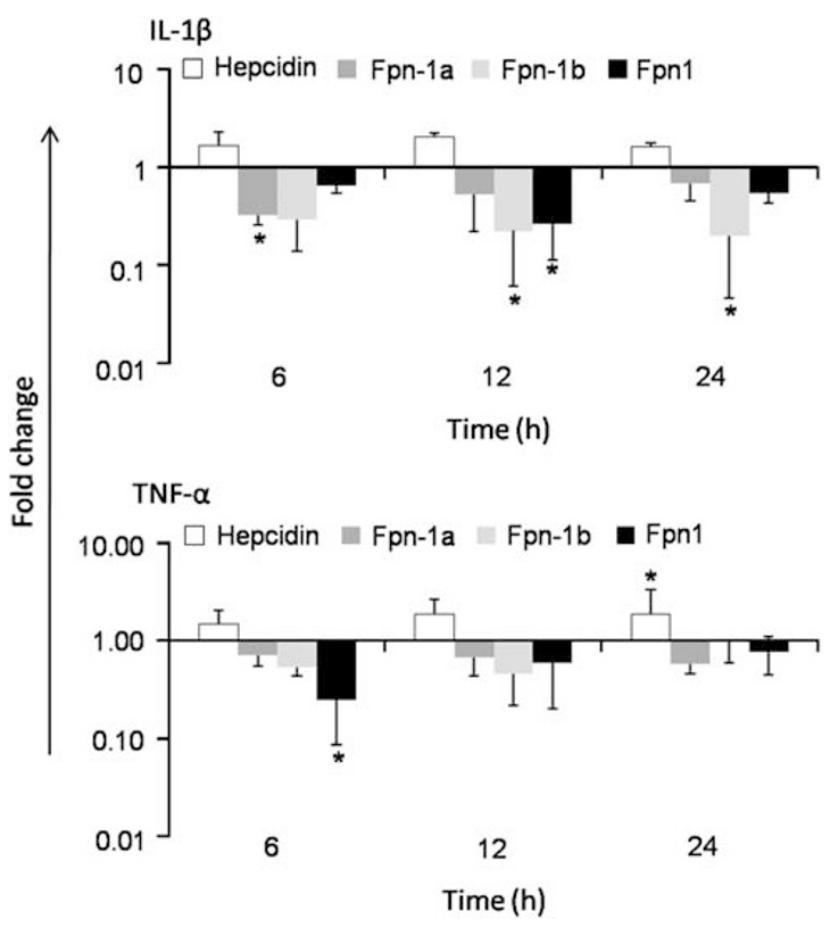

Figure 14 Quantification of hepcidin, ferroportin-1 (Fpn-1), Fpn-1 $a$ and Fpn-1b gene expression in isolated rat hepatocytes after IL-1 $\beta$ and TNF- $\alpha$ treatment. Results represent the fold changes of mRNA expression of respective gene, where the control values were normalized to one. Data show the results of three experiments (mean values \pm s.e.m., ${ }^{*} P<0.05$ analyzed by one-way analysis of variance (ANOVA)).

injury. ${ }^{46}$ In fact, the upregulation of $I L-1 \beta$ and $T N F-\alpha$ gene expression is more intense in the injured muscle of IL-6 knock-out mice than in their wild-type littermate. ${ }^{46}$ Therefore, we hypothesized that Fpn-1 is mainly controlled by IL-6 and partially by other acute-phase cytokines (IL- $1 \beta$ and TNF- $\alpha$ ), which are released at the site of injury during APR. ${ }^{25,27}$
Table 4 Comparison of changes in mRNA amount of Fpn-1 and its isoforms after cytokine stimulation

\begin{tabular}{lccc}
\hline Gene & \multicolumn{3}{c}{ Changes in mRNA amount } \\
\cline { 2 - 4 } & IL-6 stimulation & IL-1 $\boldsymbol{\beta}$ stimulation & TNF- $\boldsymbol{\alpha}$ stimulation \\
\hline Fpn-1 & $0.11 \pm 0.07$ & $0.31 \pm 0.15$ & $0.24 \pm 0.16$ \\
Fpn-1 $a$ & $0.11 \pm 0.04$ & $0.33 \pm 0.07$ & $0.6 \pm 0.23$ \\
Fpn-1b & $0.10 \pm 0.03$ & $0.2 \pm 0.15$ & $0.5 \pm 0.25$
\end{tabular}

Abbreviation: Fpn-1, ferroportin-1.
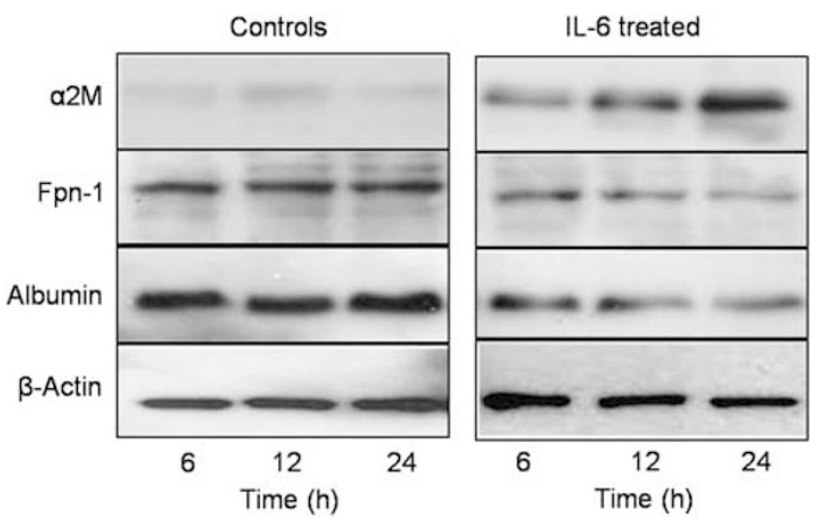

Figure 15 Western blot analysis of control and IL-6-treated rat hepatocytes for alpha-2-macroglobulin ( $\alpha 2 \mathrm{M})$, ferroportin-1 (Fpn-1) and albumin protein. Changes in protein expression of $\alpha 2 \mathrm{M}$ (a positive acute-phase protein (APP)), albumin (a negative acute-phase protein) and Fpn-1 (the iron export protein) in control and IL-6-treated hepatocytes. Immunodetection by western blot analysis showed an increase in $\alpha 2 \mathrm{M}$ protein, whereas Fpn-1 and albumin protein expression was downregulated after stimulation with IL-6. Data show the results of three experiments.

Moreover, these cytokines could also modulate the gene expression of other iron transport proteins. ${ }^{47,48}$ In fact, the findings presented here are consistent with earlier studies obtained at RNA level, wherein a downregulation of Fpn-1specific transcripts occurred in parallel with an increase in the level of the acute-phase cytokines (IL-6, IL-1 $\beta$ and TNF- $\alpha$ ) reported in different rat models. ${ }^{48-50}$ Furthermore, in our current study, treatment of rat hepatocytes with cytokines (IL-6, IL-1 $\beta$ and TNF- $\alpha$ ) reduced the Fpn-1 gene expression; however, the impact of IL-6 was the strongest compared with that induced by the two other cytokines.

Taken together, it became evident that early-observed hepatic Fpn-1 reduction could be due to direct effect of the acute-phase cytokines, ${ }^{25,48}$ whereas late decrease in Fpn-1 protein could be due to the combination of both hepcidin and the acute-phase cytokines.

An upregulation of hepatic DMT-1, Tf, TfR 1 and TfR2 in parallel to the increase in hepatic iron content supports an increased iron uptake during the APR. Although gene 
expression of DMT-1 and TfR1 is thought to be inversely regulated by the cellular iron stores via posttranscriptional IRE-iron regulatory protein mechanism, ${ }^{10,51}$ the upregulation of gene expression of DMT-1 and TfR 1 in the present study consisting of the effect of an APR might be attributable to either an activation of IRP-1 or hypoxia-inducible factor$1 \alpha$ (HIF- $1 \alpha),{ }^{52,53}$ both of which bind to a conserved binding site within the TfR 1 and DMT-1 promoter. ${ }^{52,54}$ It should be noted that an induction of hepatic IRP ${ }_{-}^{25}$ and HIF- $1 \alpha^{46}$ gene expression has been reported in the APR model utilized in the present experiments. The upregulation of these iron transport molecules may also be due to an action of the major acute-phase cytokine (IL-6) as shown previously in vitro. ${ }^{55}$

In summary, we propose that under normal conditions, portal blood iron is taken up by liver cells through a TfR1mediated iron uptake pathway. Once within the cell, the iron is delivered not only to cytoplasmic organelles such as mitochondria, ${ }^{56}$ but also to the nucleus. Under acute-phase conditions, the rapid reduction in serum iron concentration is most probably achieved by the increase of hepatic uptake of Tf-bound iron by the TfR1-mediated iron transport system. Accordingly, a reduction in Fpn-1 (by acute-phase cytokines and hepcidin-mediated internalization) and hephastin results in transient iron retention within the cell and its nucleus to meet the functional requirements of the acutephase condition.

Supplementary Information accompanies the paper on the Laboratory Investigation website (http://www.laboratoryinvestigation.org)

\section{ACKNOWLEDGEMENT}

We thank Mrs S Zachmann, Mrs D Gerke and Mrs D Fey for their kind and skillful technical assistance. This work has been supported by Grants of Deutsche Krebshilfe (Project 108774). This work is dedicated by NN, IM, NS, SA, SK, MB and FS to Professor Dr Giuliano Ramadori on the occasion of his 60th birthday.

\section{DISCLOSURE/CONFLICT OF INTEREST}

The authors declare no conflict of interest.

1. Nemeth E, Ganz T. Regulation of iron metabolism by hepcidin. Annu Rev Nutr 2006;26:323-342.

2. Ganz T. Cellular iron: ferroportin is the only way out. Cell Metab 2005;1:155-157.

3. Piñero DJ, Connor JR. Iron in the brain: an important contributor in normal and diseased states. Neuroscientist 2000;6:435-453.

4. Gunshin $\mathrm{H}$, Allerson CR, Polycarpou-Schwarz M, et al. Iron-dependent regulation of the divalent metal ion transporter. FEBS Lett 2001; 509:309-316.

5. Gruenheid S, Canonne-Hergaux F, Gauthier S, et al. The iron transport protein NRAMP2 is an integral membrane glycoprotein that colocalizes with transferrin in recycling endosomes. J Exp Med 1999;189:831-841.

6. Tabuchi M, Yoshimori T, Yamaguchi K, et al. Human NRAMP2/DMT1, which mediates iron transport across endosomal membranes, is localized to late endosomes and lysosomes in HEp-2 cells. J Biol Chem 2000;275:22220-22228.

7. Hentze MW, Muckenthaler MU, Galy B, et al. Two to tango: regulation of mammalian iron metabolism. Cell 2010;142:24-38.

8. Prus $E$, Fibach E. Uptake of non-transferrin iron by erythroid cells. Anemia 2011;2011:945289.

9. Frazer DM, Anderson GJ. Iron imports. I. Intestinal iron absorption and its regulation. Am J Physiol Gastrointest Liver Physiol 2005;289: G631-G635.
10. Levy JE, Jin O, Fujiwara $Y$, et al. Transferrin receptor is necessary for development of erythrocytes and the nervous system. Nat Genet 1999;21:396-399.

11. Roetto A, Di CF, Pellegrino RM, et al. Comparison of 3 Tfr2-deficient murine models suggests distinct functions for Tfr2-alpha and Tfr2-beta isoforms in different tissues. Blood 2010;115:3382-3389.

12. Nemeth $\mathrm{E}$, Tuttle MS, Powelson J, et al. Hepcidin regulates cellular iron efflux by binding to ferroportin and inducing its internalization. Science 2004;306:2090-2093.

13. Donovan A, Brownlie A, Zhou Y, et al. Positional cloning of zebrafish ferroportin 1 identifies a conserved vertebrate iron exporter. Nature 2000;403:776-781.

14. Abboud S, Haile DJ. A novel mammalian iron-regulated protein involved in intracellular iron metabolism. J Biol Chem 2000;275: 19906-19912.

15. Petrak J, Vyoral D. Hephaestin-a ferroxidase of cellular iron export. Int J Biochem Cell Biol 2005;37:1173-1178.

16. Han O, Kim EY. Colocalization of ferroportin-1 with hephaestin on the basolateral membrane of human intestinal absorptive cells. J Cell Biochem 2007;101:1000-1010.

17. Vulpe CD, Kuo YM, Murphy TL, et al. Hephaestin, a ceruloplasmin homologue implicated in intestinal iron transport, is defective in the sla mouse. Nat Genet 1999;21:195-199.

18. Ramey G, Deschemin JC, Durel B, et al. Hepcidin targets ferroportin for degradation in hepatocytes. Haematologica 2010;95:501-504.

19. Aydemir F, Jenkitkasemwong S, Gulec $S$, et al. Iron loading increases ferroportin heterogeneous nuclear RNA and mRNA levels in murine J774 macrophages. J Nutr 2009;139:434-438.

20. Yeh KY, Yeh M, Mims L, et al. Iron feeding induces ferroportin 1 and hephaestin migration and interaction in rat duodenal epithelium. Am J Physiol Gastrointest Liver Physiol 2009;296:G55-G65.

21. Liu XB, Hill P, Haile DJ. Role of the ferroportin iron-responsive element in iron and nitric oxide dependent gene regulation. Blood Cells Mol Dis 2002;29:315-326.

22. Zhang $\mathrm{DL}$, Hughes $\mathrm{RM}$, Ollivierre-Wilson $\mathrm{H}$, et al. A ferroportin transcript that lacks an iron-responsive element enables duodenal and erythroid precursor cells to evade translational repression. Cell Metab 2009;9:461-473.

23. Ganz T. Hepcidin and iron regulation, 10 years later. Blood 2011; 117:4425-4433.

24. Cairo G, Recalcati S, Mantovani A, et al. Iron trafficking and metabolism in macrophages: contribution to the polarized phenotype. Trends Immunol 2011;32:241-247.

25. Sheikh N, Dudas J, Ramadori G. Changes of gene expression of iron regulatory proteins during turpentine oil-induced acute-phase response in the rat. Lab Invest 2007:87:713-725.

26. Uchida T, Igarashi T, Suzuki T, et al. The effect of acute inflammation on iron metabolism in rats. Tohoku J Exp Med 1983;139:293-298.

27. Malik IA, Naz N, Sheikh $N$, et al. Comparison of changes in gene expression of transferrin receptor-1 and other iron-regulatory proteins in rat liver and brain during acute-phase response. Cell Tissue Res 2011;344:299-312.

28. Viatte $\mathrm{L}$, Grone HJ, Hentze MW, et al. In vivo role(s) of the iron regulatory proteins (IRP) 1 and 2 in aseptic local inflammation. J Mol Med (Berl) 2009;87:913-921.

29. Tron K, Novosyadlyy R, Dudas J, et al. Upregulation of heme oxygenase-1 gene by turpentine oil-induced localized inflammation: involvement of interleukin-6. Lab Invest 2005;85:376-387.

30. Riemer J, Hoepken $\mathrm{HH}$, Czerwinska $\mathrm{H}$, et al. Colorimetric ferrozinebased assay for the quantitation of iron in cultured cells. Anal Biochem 2004;331:370-375.

31. Budick-Harmelin N, Dudas J, Demuth J, et al. Triglycerides potentiate the inflammatory response in rat Kupffer cells. Antioxid Redox Signal 2008;10:2009-2022.

32. Wang $\mathrm{RH}, \mathrm{Li} \mathrm{C}, \mathrm{XuX}$, et al. A role of SMAD4 in iron metabolism through the positive regulation of hepcidin expression. Cell Metab 2005;2: 399-409.

33. Valenzuela $C$, de Romana $\mathrm{DL}$, Olivares $\mathrm{M}$, et al. Total iron and heme iron content and their distribution in beef meat and viscera. Biol Trace Elem Res 2009;132:103-111.

34. Ahmad KA, Ahmann JR, Migas MC, et al. Decreased liver hepcidin expression in the Hfe knockout mouse. Blood Cells Mol Dis 2002; 29:361-366. 
35. Zhou XY, Tomatsu S, Fleming RE, et al. HFE gene knockout produces mouse model of hereditary hemochromatosis. Proc Natl Acad Sc 1998;95:2492-2497.

36. Sciot R, Van EP, Desmet VJ. Transferrin receptor expression in benign tumours and in hepatoblastoma of the liver. Histopathology 1990;16:59-62.

37. Ramadori G, Christ B. Cytokines and the hepatic acute-phase response. Semin Liver Dis 1999;19:141-155.

38. Roth JA, Horbinski C, Feng $L$, et al. Differential localization of divalent metal transporter 1 with and without iron response element in rat PC12 and sympathetic neuronal cells. J Neurosci 2000;20:7595-7601.

39. Magens B, Dullmann J, Schumann K, et al. Nuclear iron deposits in hepatocytes of iron-loaded HFE-knock-out mice: a morphometric and immunocytochemical analysis. Acta Histochem 2005;107:57-65.

40. Smith AG, Carthew P, Francis JE, et al. Characterization and accumulation of ferritin in hepatocyte nuclei of mice with iron overload. Hepatology 1990;12:1399-1405.

41. Surguladze N, Patton S, Cozzi A, et al. Characterization of nuclear ferritin and mechanism of translocation. Biochem J 2005;388:731-740.

42. Thomas C, Oates PS. Ferroportin/IREG-1/MTP-1/SLC40A1 modulates the uptake of iron at the apical membrane of enterocytes. Gut 2004; 53:44-49.

43. Yang F, Liu XB, Quinones $M$, et al. Regulation of reticuloendothelial iron transporter MTP1 (Slc11a3) by inflammation. J Biol Chem 2002 277:39786-39791.

44. D'Anna MC, Veuthey TV, Roque ME. Immunolocalization of ferroportin in healthy and anemic mice. J Histochem Cytochem 2009;57:9-16.

45. Yang F, Haile DJ, Wang $X$, et al. Apical location of ferroportin 1 in airway epithelia and its role in iron detoxification in the lung. Am J Physiol Lung Cell Mol Physiol 2005;289:L14-L23.

46. Ramadori P, Ahmad G, Ramadori G. Cellular and molecular mechanisms regulating the hepatic erythropoietin expression during acute-phase response: a role for IL-6. Lab Invest 2010;90:1306-1324.
47. Nemeth E, Rivera S, Gabayan V, et al. IL-6 mediates hypoferremia of inflammation by inducing the synthesis of the iron regulatory hormone hepcidin. J Clin Invest 2004;113:1271-1276.

48. Sheikh N, Batusic DS, Dudas J, et al. Hepcidin and hemojuvelin gene expression in rat liver damage: in vivo and in vitro studies. Am J Physiol Gastrointest Liver Physiol 2006;291:G482-G490.

49. Christiansen $\mathrm{H}$, Sheikh $\mathrm{N}$, Saile $\mathrm{B}$, et al. x-Irradiation in rat liver: consequent upregulation of hepcidin and downregulation of hemojuvelin and ferroportin-1 gene expression. Radiology 2007;242:189-197.

50. Moriconi F, Ahmad G, Ramadori P, et al. Phagocytosis of gadolinium chloride or zymosan induces simultaneous upregulation of hepcidinand downregulation of hemojuvelin- and Fpn-1-gene expression in murine liver. Lab Invest 2009;89:1252-1260.

51. Kato J, Kobune M, Ohkubo S, et al. Iron/IRP-1-dependent regulation of mRNA expression for transferrin receptor, DMT1 and ferritin during human erythroid differentiation. Exp Hematol 2007;35:879-887.

52. Tacchini L, Bianchi L, Bernelli-Zazzera A, et al. Transferrin receptor induction by hypoxia. HIF-1-mediated transcriptional activation and cell-specific post-transcriptional regulation. J Biol Chem 1999;274: 24142-24146.

53. Tacchini L, Fusar PD, Bernelli-Zazzera A, et al. Transferrin receptor gene expression and transferrin-bound iron uptake are increased during postischemic rat liver reperfusion. Hepatology 2002;36: 103-111.

54. Qian ZM, Wu XM, Fan M, et al. Divalent metal transporter 1 is a hypoxia-inducible gene. J Cell Physiol 2011;226:1596-1603.

55. Sheikh N, Batusic DS, Dudas J, et al. Hepcidin and hemojuvelin gene expression in rat liver damage: in vivo and in vitro studies. Am J Physiol Gastrointest Liver Physiol 2006;291:G482-G490.

56. Richardson DR, Lane DJ, Becker EM, et al. Mitochondrial iron trafficking and the integration of iron metabolism between the mitochondrion and cytosol. Proc Natl Acad Sci USA 2010;107: 10775-10782. 